\title{
A Study of the Anatomical Variations in the Shape and Diameter of the Suprascapular Notch and Spinoglenoid Notch in Dried Human Scapulae
}

\author{
HANAN N. GADALLAH, M.D. and AMANY E. HAMOUD, M.D. \\ The Department of Anatomy and Embryology, Faculty of Medicine, Cairo University
}

\begin{abstract}
Background: The suprascapular notch is a depression on the superior border of scapula which gives passage to the suprascapular nerve to enter the supraspinous fossa. During its course there is a possibility of entrapment of the nerve while in the notch due to its variant shapes and dimensions which leads to suprascapular nerve entrapment syndrome. Also the spinoglenoid notch with its ligament is affected by the position of the glenohumeral joint. These pressure changes in combination with repetitive shoulder movement are likely components that cause repeated trauma or compression on the distal suprascapular nerve.
\end{abstract}

Aim of Study: The present work was designed to study the variation of the shape and diameter of the suprascapular notch and spinoglenoid notch of the scapula.

Material and Methods: The study will be carried out on 100 dried human scapula obtained from Anatomy department, Faculty of Medicine, Cairo University. The shape of the suprascapular notch was determined and recorded as follow $\mathrm{U}$ shaped, $\mathrm{V}$ shaped, flat or absent at all. Out of 100 scapulae 56 were right sided and 44 were left sided. Also the mean values for suprascapula notch was measured.

Results: The most common shape was V-shaped, followed by U-shaped, then the least common one is the flat one. About $14 \%$ scapulae showing absent foramen. Regarding the side of scapulae, V shaped suprascapular notch were recorded in $44.2 \%$ scapulae (22 left side, 16 right side), while $39.5 \%$ were U shaped (12 left side, 22 right side). Only $16.3 \%$ scapulae showed flat suprascapular notch ( 8 left side, 6 right side).

Conclusion: This study may help the clinicians to have precise anatomical knowledge of the suprascapular notch before making proper diagnosis and surgical interventions of suprascapular nerve entrapment syndrome.

Key Words: Suprascapular - Notch - Spinoglenoid - Suprascapular nerve.

Correspondence to: Dr. Hanan N. Gadallah, The Department of Anatomy and Embryology, Faculty of Medicine, Cairo University

\section{Introduction}

THE Scapula is a flat triangular bone that lies on the posterior chest wall between the second and seventh rib and has three borders (superior, medial, and lateral) and three angles (superior, inferior, and lateral). The superior border extends from the superior angle to the lateral angle. It is the thinnest and the shortest of the three borders. Near the root of the coracoid process, the superior border presents a notch called the suprascapular notch (SSN). This notch is converted into a foramen, called the suprascapular foramen, by the attachment of the superior transverse scapular ligament to its edges [1].

After arising from the upper trunk of the brachial plexus, the suprascapular nerve passes through this foramen and supplies the supraspinatus muscle. As the nerve travels laterally along the supraspinous fossa, it approaches the posterior glenoid rim, around the scapular spine, and descends into the infraspinous fossa and passes under the spinoglenoid ligament (inferior transverse scapular ligament) along with the suprascapular vessels to supply the infraspinatus muscle. It also gives a twig to the shoulder joint [2]. Overhead abduction of the shoulder joint exerts traction on the suprascapular nerve and leads to its compression [3]

SSN was described as a depression present on the lateral aspect of superior border of the scapula just medial to the coracoid process [4,5] . They added that in few cases, this notch may be transformed into a foramen due to ossification of suprascapular ligament (STSL) and serves as a bony tunnel for suprascapular nerve. So the authors concluded that the shape and size of the SSN is the most important causal factor in the pathogenesis of suprascapular nerve entrapment syndrome. 
The suprascapular nerve compression may result in significant dysfunction of rotator cuff [6]. This disease is characterized by dull aching pain over the posterolateral region of the shoulder, atrophy of the supraspinatus and infraspinatus muscles and weakness during external rotation and initiation of shoulder abduction [2,7]. The anatomical variations of the suprascapular notch in combination with superior transverse scapular ligament are responsible for suprascapular nerve entrapment syndrome $[8,9]$

Previously, cadaveric study was performed and found that the spinoglenoid ligament was present in $100 \%$ of specimens [10]. The authors also found that it had attachments to the glenohumeral joint, which contributed to compression of the suprascapular nerve at the spinoglenoid ligament on internal rotation of the shoulder.

Although the usual site of suprascapular entrapment neuropathy is at the transverse scapular ligament in the suprascapular foramen, clinical presentation and diagnosis of compression have been recorded [11]. Most commonly in overhead athletes, injury to this nerve may occur from repetitive traction and microtrauma [12].

The spinoglenoid ligament has also been demonstrated to tighten when the shoulder is in a position for overhead throwing, resulting in increased pressure on the suprascapular nerve [13] A stenotic notch, ossified spinoglenoid ligament, or even superiorly oriented fibers of the subscapularis muscle may cause suprascapular neuropathy [14].

The aim of this study is study the variations in the shape of the suprascapular notch.

\section{Patients and Methods}

The present study was done on 100 dry adult human scapulae of both sex obtained from Anatomy Department, Cairo University, 2018. The shape of suprascapular notch was determined and recorded. Out of 100 scapulae 56 were right sided and 44 were left sided. But exact age and gender were not known.

Inclusion criteria: All the scapulae were completely ossified and without any deformity.

Exclusion criteria: Scapulae with deformity, pathology or with any fracture.
The following parameters were measured for suprascapular notch using vernier sliding caliper [15] as follow:

1- Superior transverse diameter (STD) the maximum value of the horizontal measurements taken in the horizontal plane between the corners of the SSN on the superior border of the scapula (Fig. 1).

2- Middle transverse diameter (MTD) the maximum horizontal distance between the margins of the notch, perpendicular to the midpoint of the vertical diameter. (Fig. 1).

3- Spinoglenoid notch diameter (Fig. 2).

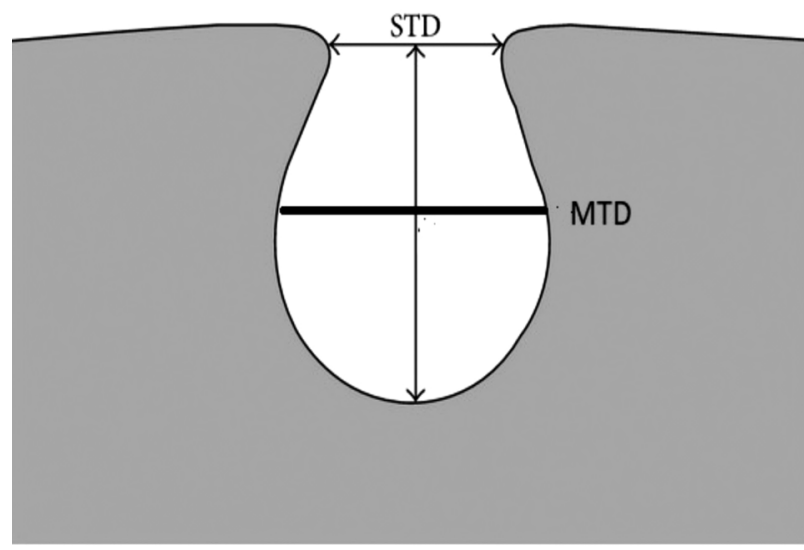

Fig. (1): Diagramtic picture showing how to measure STD and MTD.

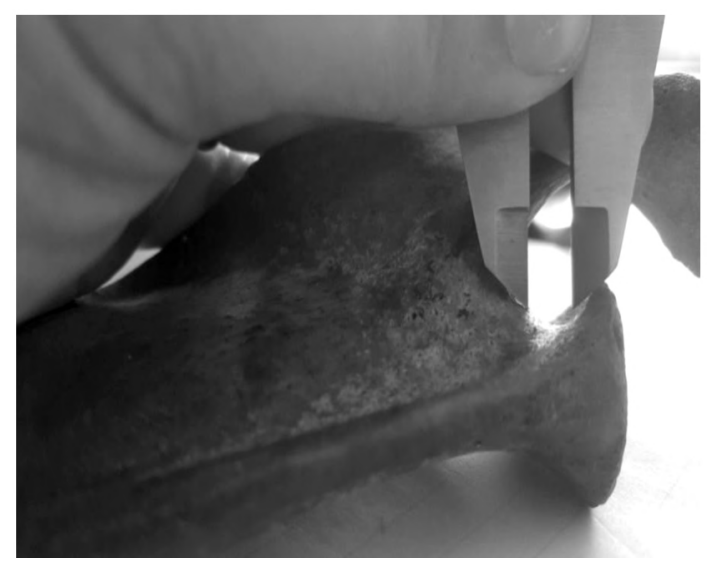

Fig. (2): Showing how to measure spinoglenoid notch.

\section{Results}

The present study was done on 100 dry human scapulae obtained from Anatomy Department, Cairo University. The shape of suprascapular notch was determined and recorded as follow U shaped, $\mathrm{V}$ shaped, flat or absent at all (Figs. 3-7). Out of 100 scapulae 56 were right sided and 44 were left sided. (Fig. 8, Table 1). 
The most common shape was $\mathrm{V}$ shaped which constitutes $38 \%$, followed by U shaped in $34 \%$, then the least common one is the flat one $14 \%$. About 14 scapulae (14\%) showing absent foramen (Table 2, Fig. 11). Regarding the side of scapulae $\mathrm{V}$ shaped suprascapular notch were recorded in 38 scapulae (22 left side, 16 right side), while 34 were U shaped (12 left side, 22 right side). Only 8 scapulae showed flat suprascapular notch $(8 \mathrm{left}$ side, 6 right side) (Fig.9, Table 2). Also suprascapular foramen was noticed (Fig. 10).

The following parameters were measured for suprascapular notch using vernier sliding caliper as follow:

\section{1- Superior transverse diameter.}

\section{2- Middle transverse diameter.}

The mean value of each was measured and subjected statistically as the mean value for superior tranverse diameter was $4.44 \mathrm{~mm}$, and for middle transverse diameter were $2.69 \mathrm{~mm}$.

Also the mean value for spinoglenoid notch was measured and tabulated (Table 3).

In respect to scapula side, mean value of superior transverse diameter on right side was 4 and 4.9 on left side. While mean value of middle transverse diameter 2.26 on right side and 3. 15 on left side. Mean value for spinoglenoid notch was 4.18 on right side and 4.96 on left side (Table 4).

Superior transverse diameter was found to be greater than middle transverse diameter in 8 scapulae $(9.3 \%)$, while middle diameter was greater in 76 scapulae $(88.4 \%)$ and both diameters were equal in two scapulae (2.35) (Table 5, Fig. 11).

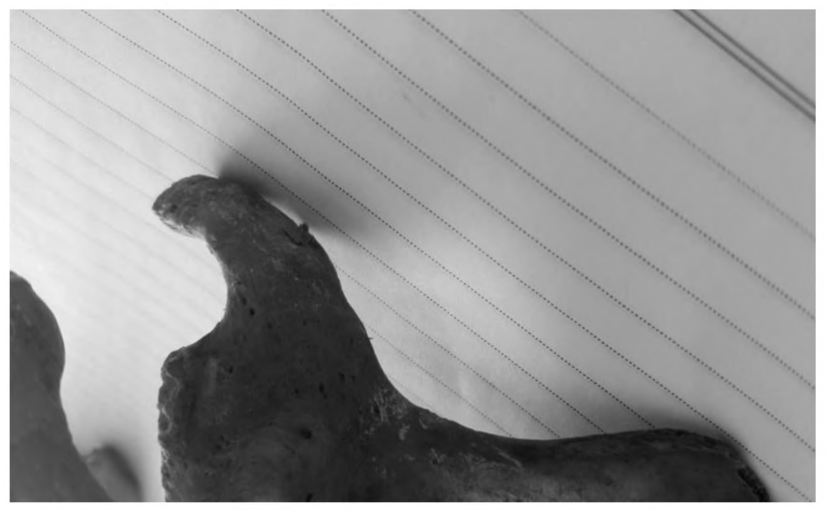

Fig. (3): Showing absence of suprascapular notch.

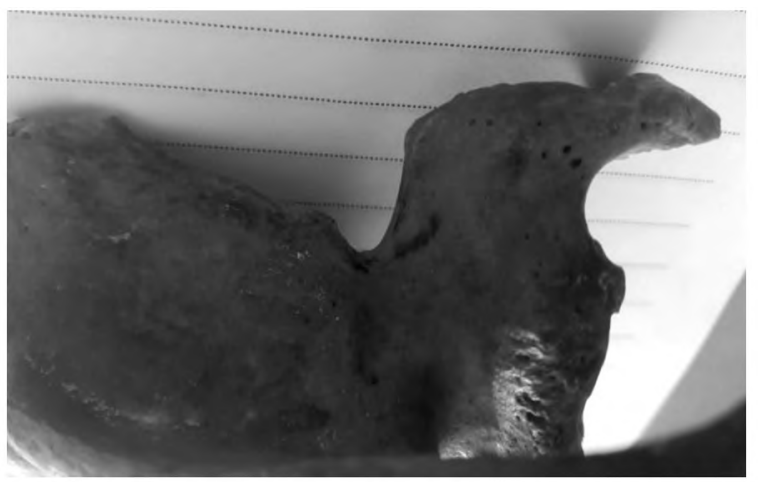

Fig. (4): Showwing V-shaped supprascappulkar motth.

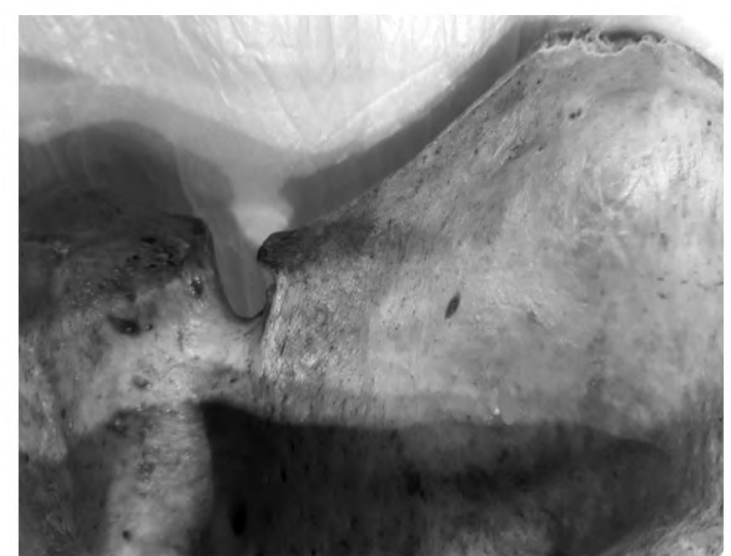

Fig. (5): Showing U-shaped suprascappullar mottcth.

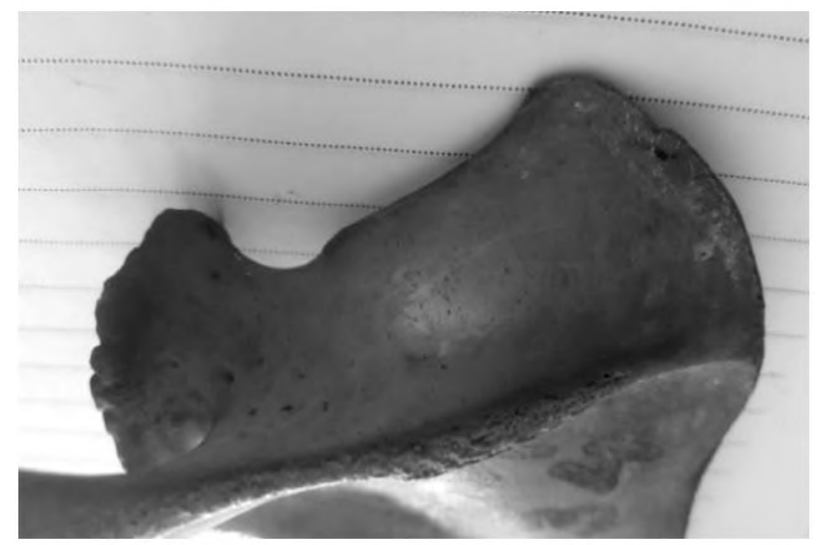

Fig. (6): Showing flat supprascanpullar motth.

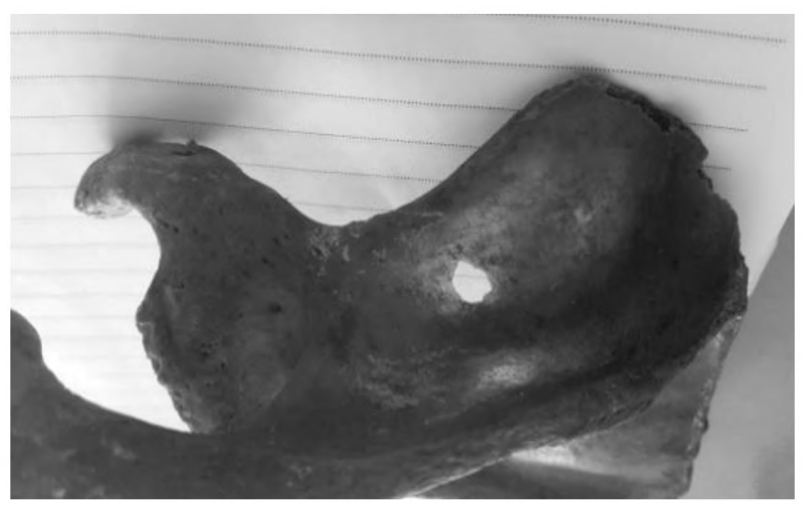

Fig. (7)): Shrowiumg suprasscapulkerfforanoen. 
Table (1): Showing percentage of side of scapulae.

\begin{tabular}{lcc}
\hline Side & Frequency & Percent \\
\hline Right & 56 & 56.0 \\
Left & 44 & 44.0 \\
\hline Total & 100 & 100.0 \\
\hline
\end{tabular}

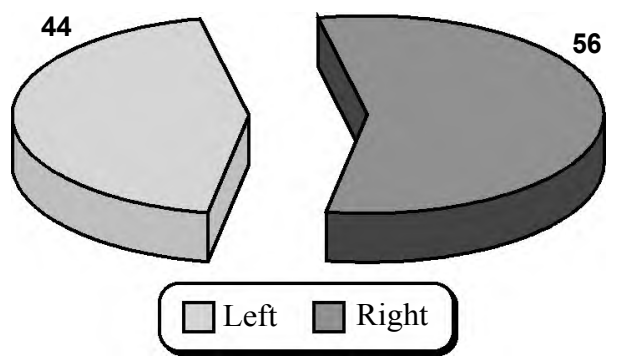

Fig. (8): Pie chart showing percentage of side of scapulae.

Table (2): Showing percentage of suprascapular shape.

\begin{tabular}{lcc}
\hline & Frequency & Percent \\
\hline V shape & 38 & 38.0 \\
U shape & 34 & 34.0 \\
Absent & 14 & 14.0 \\
Flat & 14 & 14.0 \\
\hline Total & 100 & 100.0 \\
\hline
\end{tabular}
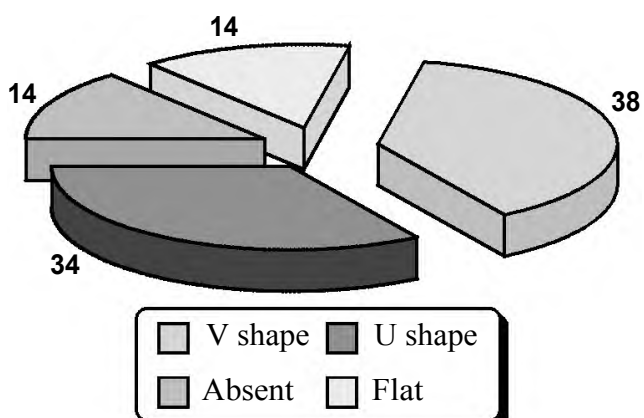

Fig. (9): Pie chart showing percentage of suprascapular shape.

Table (3): Showing side of scapulae and shape of suprascapular notch

\begin{tabular}{|c|c|c|c|}
\hline & \multicolumn{2}{|c|}{ Side } & \multirow{2}{*}{ Total } \\
\hline & Right & Left & \\
\hline \multicolumn{4}{|l|}{ Shape: } \\
\hline \multicolumn{4}{|l|}{ V shape: } \\
\hline Count & 16 & 22 & 38 \\
\hline$\%$ within shape & $42.1 \%$ & $57.9 \%$ & $100.0 \%$ \\
\hline \multicolumn{4}{|l|}{ U shape: } \\
\hline Count & 22 & 12 & 34 \\
\hline$\%$ within shape & $64.7 \%$ & $35.3 \%$ & $100.0 \%$ \\
\hline \multicolumn{4}{|l|}{ Flat: } \\
\hline Count & 6 & 8 & 14 \\
\hline$\%$ within shape & $42.9 \%$ & $57.1 \%$ & $100.0 \%$ \\
\hline \multicolumn{4}{|l|}{ Total } \\
\hline Count & 44 & 42 & 86 \\
\hline$\%$ within shape & $51.2 \%$ & $48.8 \%$ & $100.0 \%$ \\
\hline
\end{tabular}

$p$-value $=0.127$

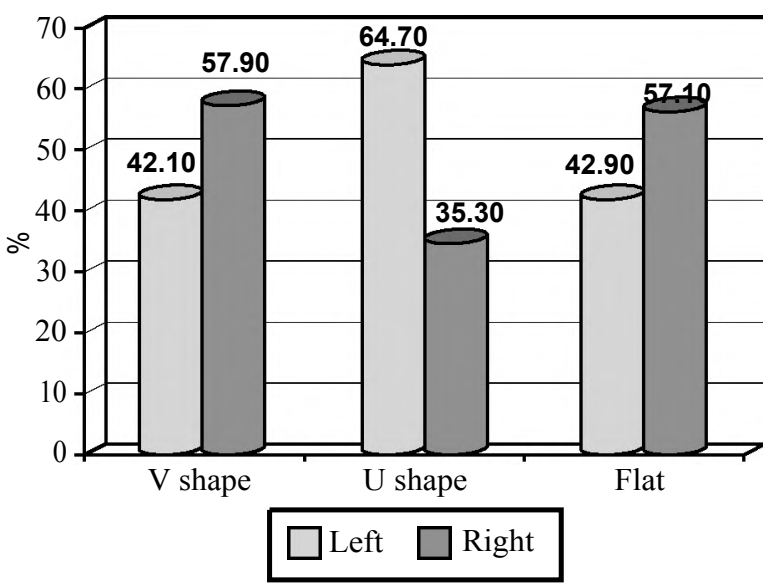

Fig. (10): Bar chart showing side and shape of suprascapular notch.

Table (4): Showing the mean values of measurement of scapulae $(\mathrm{mm})$.

\begin{tabular}{lllllll}
\hline & $\mathrm{N}$ & Range & $\begin{array}{c}\text { Mini- } \\
\text { mum }\end{array}$ & $\begin{array}{c}\text { Maxi- } \\
\text { mum }\end{array}$ & Mean & $\begin{array}{c}\text { Std. } \\
\text { Deviation }\end{array}$ \\
\hline STD & 86 & 13.95 & 0.48 & 14.43 & 4.4458 & 3.19793 \\
MTD & 86 & 9.32 & .0 .01 & 9.33 & 2.6986 & 2.47963 \\
$\begin{array}{c}\text { Spinog- } \\
\text { lenoid }\end{array}$ & 86 & 12.73 & 0.20 & 12.93 & 4.5686 & 3.50238 \\
\hline
\end{tabular}

STD : Superior transverse diameter.

MTD: Middle transverse diameter.

Table (5): Showing diameters measurement in respect to side.

\begin{tabular}{lllccc}
\hline & Side & $\mathrm{N}$ & Mean & $\begin{array}{c}\text { Std. } \\
\text { Deviation }\end{array}$ & $p$-value \\
\hline STD & Right & 44 & 4.0032 & 2.64672 & .191 \\
& Left & 42 & 4.9095 & 3.66394 & \\
MTD & Right & 44 & 2.2659 & 1.83797 & .098 \\
& Left & 42 & 3.1519 & 2.96524 & \\
Spinoglenoid & Right & 44 & 4.1877 & 2.70680 & .305 \\
& Left & 42 & 4.9676 & 4.17468 & \\
\hline
\end{tabular}

Table (6): Relation between superior and middle tranverse diameter.

\begin{tabular}{lcl}
\hline & Frequency & Percent \\
\hline Valid: & & \\
Std more & 8 & 9.3 \\
Equal & 2 & 2.3 \\
Mtd more & 76 & 88.4 \\
\hline Total & 86 & 100.0 \\
\hline
\end{tabular}

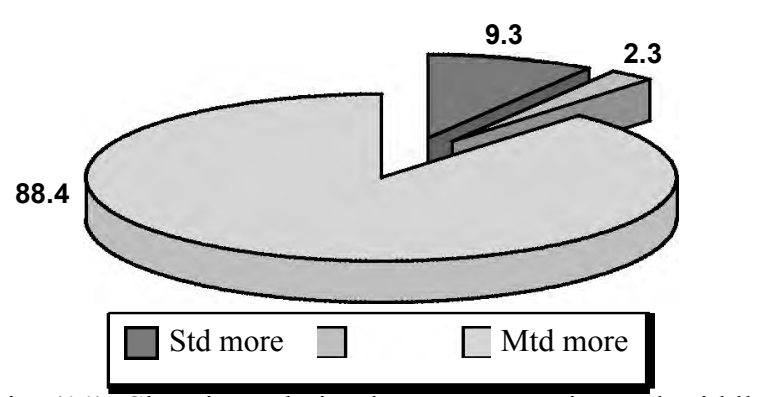

Fig. (11): Showing relation between superior and middle transverse diameter. 


\section{Discussion}

Knowledge of detail anatomy of suprascapular notch (SSN) is necessary for proper diagnosis and treatment of shoulder girdle problems that might be related to the nerve. In the present study, an effort has been made to classify suprascapular notch based on its shape and dimensions. Various authors have classified SSN based on certain parameters and gross examination of its shape.

SSN have been classified on the basis of morphological appearance into two types $U \& \mathrm{~V}$ and found U-shaped notch to be the most common type $[16,17]$. Moreover, another classification of SSN into three types $\mathrm{U}, \mathrm{V}, \mathrm{J}$ based on their shapes on gross examination [18]. Five types of SSN were reported as $\mathrm{U}, \mathrm{V}, \mathrm{J}$, indentation and absence of the notch [13].

The current study predominately showed four types $\mathrm{V}$, U, flat and absent notch. The most common type was $\mathrm{V}$-shaped one which constitutes $44.2 \%$, followed by U-shaped in $39.5 \%$, then the least common one is the flat one $16.3 \%$. About 14 scapulae (14\%) showing absent foramen.

The highest incidence of V-shaped suprascapular notch, thus having a higher predisposition to suprascapular nerve entrapment neuropathy [19] The authors added that the U-shaped suprascapular notch, defined as having approximately parallel sides with a rounded base, and the V-shaped suprascapular notch, defined as having medial and lateral sides which converge toward a narrow base. Suprascapular nerve entrapment is more likely to be associated with a narrow V-shaped notch. They noticed also that a reduction in the height of the suprascapular foramen may predispose to entrapment of the suprascapular nerve and it should be considered as a possible etiologic factor in suprascapular nerve entrapment.

Suprascapular nerve entrapment is an acquired neuropathy secondary to compression of the nerve in the bony suprascapular notch. The suprascapular notch is frequently bridged by bone rather than a ligament, converting it into foramen in some animals but incidence is much less in humans [20]

Also compression of the nerve may occur at the spinoglenoid ligament and that has been noted by many authors to be caused by a soft tissue mass or ganglion cyst as a result of some form of a labral or capsule injury [21]
Compression by a ganglion cyst or soft tissue mass has known to occur because of the relatively fixed position of the suprascapular nerve combined with the close proximity of the infraspinatus muscle to the glenohumeral joint. These ganglia may form when the capsule or labrum tears and synovial fluid is forced into the tissues as a 1-way valve, similar to meniscal cysts that occur in the knee [21].

Irrespective of the mechanism, compression or injury to the suprascapular nerve at the spinoglenoid ligament results in weakness and, if long term, atrophy of the infraspinatus muscle, with little, if any, probability of return to normal muscle strength.

Using the present study, the clinician will be able to define easily and quickly the notch type on a plain radiograph and perhaps is able to correlate suprascapular nerve entrapment.

\section{References}

1- STANDRING S.: Greys Anatomy. $40^{\text {th }}$ ed. New York: Churchill Livingstone, p. 794-821, 2008.

2- MCMINN R.M.: Last's Anatomy. $9^{\text {th }}$ ed. UK: Churchill Livingstone, p. 68, 2009.

3- KHAN M.A.: Complete ossification of the superior transverse scapular ligament in an Indian male adult. Int. J. Morphol,, 24: 195-6, 2006.

4- NATSIS K., TOTLIS T. and TSIKARAS P.: J. Proposal for classification of the suprascapular notch: A studyon 423 dried scapulas. Clin. Anat., 20: 135-39, 2007.

5- APURBA P., MANJEET S. and HARSIMARJIT K.: Variations in the Shape and Dimension of the Suprascapular Notch in Dried Human Scapula-An osteological Study with its Clinical Implications. International Journal of Anatomy, Radiology and Surgery, 5 (2): 1-5, 2016.

6- KOPELL H. and THOMPSON W.: Pain and the frozen shoulder. Surg. Gynecol. Obstet., 109: 92-96, 1959.

7- ANTONIOU J., TAE S. and WILLIAMS G.: Suprascapular neuropathy: Variability in the diagnosis, treatment and outcome. Clin. Orthop. Relat. Res., 386: 13 1-3 8, 2001.

8- RUBI S., RUPAK J. and BANANI D.: Variations in the Shape of the Suprascapular Notch in Dry Human Scapula: An Anatomical Study. International Journal of Scientific Study, 5 (1): 188-190,2017.

9- JADHAV S., PATIL R. and ROY P.: Suprascapular foramen in Indian dry scapulae. National Journal of Clinical Anatomy, 1 (3): 133-135, 2012.

10- VYAS K., RAJPUT H. and ZANZRUKIYA K.: Various dimensions of safe zone to prevent suprascapular nerve injury. Indian Journal of Applied Basic Medical Sciences, 15a, (20): 27-39, 2013

11- KEVIN D., PLANCHER M. and STEPHANIE C.: Posterior Shoulder Pain and Arthroscopic Decompression of the Suprascapular Nerve at the Spinoglenoid Notch. Oper. Tech. Sports Med., 22: 73-87. 2014. 
12- PLANCHER K., LUKE T. and PETERSON R.: Posterior shoulder pain: A dynamic study of the spinoglenoid ligament and treatment with arthroscopic release of the scapular tunnel. Arthroscopy, 23: 991-998, 2007.

13- LAJTAI G., WIESER K. and OFNER M.: Electromyography and nerve conduction velocity for the evaluation of the infraspinatus muscle and the suprascapular nerve in professional beach volleyball players. Am. J. Sports Med., 40: 2303-2308, 2012.

14- PLANCHER K., PETERSON R. and JOHNSTON J.: The spinoglenoid ligament. Anatomy, morphology, and histological findings. J. Bone. Joint. Surg. Am., 87: 361$365,2005$.

15- REDDY MURALIDHAR S., SARADA DEVI S.S., KRUPADANAM K. and ANASUYA K.: A study on the morphology of the Suprascapular notch and its distance from the glenoid covity. J. Clin. Diagn. Res., 7 (2): 189-92, 2013.

16- BAYRAMOGLU A., DEMIRYUREK D. and TUCCAR E.: Variations in Anatomy at the suprascapular notch possibly causing suprascapular nerve entrapment: An
Anatomical study. Knee. Surg. Sport. Trauma. Arthrosc., 11: 393-398, 2003.

17- SINKEET K., AWORI P. and ODUIA J.: The suprascapular notch: Its morphology and distance from the glenoid cavity in a Kenyan population. Folia Morphol., 69 (4): 241-245, 2010.

18- IQBAL K., IQBAL R. and KHAN S.: Anatomical variations in shape of suprascapular notch of scapula. J. Morphol. Sci., 27 (1): 1-2, 2010.

19- GIRISH V., SHISHIRKUMAR and APOORVA D.: Study of Morphological Variations of Suprascapular Notch in Human Dry Scapulae of South Indians. International Journal of Scientific and Research Publications, 4 (9): 14, 2014.

20- WESTERHEIDE K., DOPIRAK R. and KARZEL R.: Suprascapular nerve palsy secondary to spinoglenoid cysts: Results of arthroscopic treatment. Arthroscopy, 22: 721-727, 2006.

21- MOORE T., FRITTS H. and QUICK D.: Suprascapular nerve entrapment caused by supraglenoid cyst compression. J. Shoulder. Elbow. Surg., 6: 455-462, 1997.

\section{دراسة للأختلاوفات التشريحية فى شكل وقطر الثلمة فوق الكتفية و الثلمة الشوكية فوق الكتف في عظام

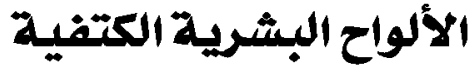

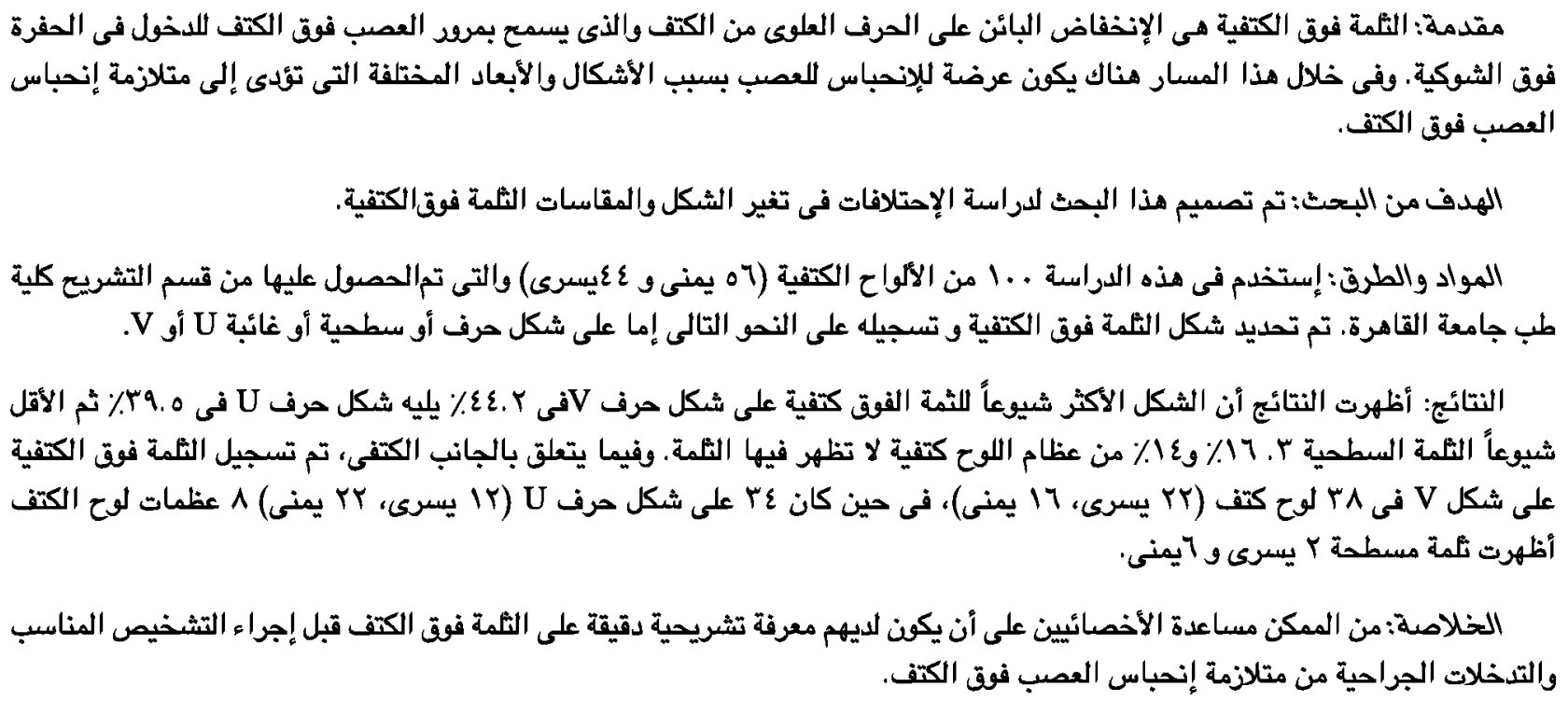

